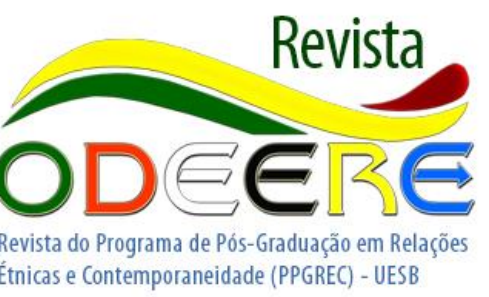

Ensino de História da África e o conceito de consciência histórica de Jörn Rüsen:

\title{
um estudo de caso
}

a partir de uma

turma do $8^{\circ}$ Ano da rede municipal de São Paulo

\author{
Helena Wakim Moreno \\ Universidade de São Paulo \\ (USP) \\ helenawakim@gmail.com
}

Resumo: Passados mais de dez anos da promulgação da lei 10.639/2003, que entre outras deliberações tornou obrigatório o ensino de história da África no Brasil, a temática paulatinamente vem ganhando espaço na sala de aula pelo crescente reconhecimento do seu papel como um agente de promoção da cidadania através do acesso à memória e à história dos afrobrasileiros e do Brasil, como nação. Este estudo se serve da noção de tipologia da consciência histórica estabelecida por Jörn Rüsen para investigar como alunos do oitavo ano de uma Escola Municipal de Ensino Fundamental (EMEF) de São Paulo têm pensado a África, os africanos e sua história a partir dos conhecimentos obtidos na escola e reavaliado suas percepções anteriores sobre tema.

Palavras-chave: História da África, Ensino de História, Consciência Histórica.

Abstract: More than ten years after the enactment of Law 10.639/2003, which among other decisions made mandatory the teaching of History of Africa in Brazil, the subject has gradually been gaining ground in the classroom by the growing recognition of its role as a promotional agent of citizenship, through access to the memory and history of the African-Brazilians and Brazil, as a nation. This study uses the typology notion of the historical awareness established by Jörn Rüsen, in order to investigate how students of the eighth grade of a Public Elementary School (EMEF) in São Paulo have been thinking of Africa, the Africans and their history, based on the knowledge obtained at 1, volume 1, Janeiro - Junho de 2016. 
school and reevaluating their previous perceptions about the subject.

Key-words: History of Africa, History teaching, Historical Awareness.

\section{A África e os africanos na sala de aula}

Após um longo histórico de reivindicações de movimentos da sociedade civil ligados à promoção da igualdade racial, foi aprovada em 10 de janeiro de 2003 a lei 10.639, que instituiu o ensino de história e cultura da África e afro-brasileira como conteúdo obrigatório na educação básica. A lei estabelece:

Lei no. 10.639 de 20 de janeiro de 2003 - Altera a Lei no 9.394, de 20 de dezembro de 1996, que estabelece as diretrizes e bases da educação nacional, para incluir no currículo oficial da Rede de Ensino a obrigatoriedade da temática "História e Cultura Afro-Brasileira", e dá outras providências.

Art. 26-A. Nos estabelecimentos de ensino fundamental e médio, oficiais e particulares, torna-se obrigatório o ensino sobre História e Cultura Afro-Brasileira. $\S 1^{\circ} \mathrm{O}$ conteúdo programático a que se refere o caput deste artigo incluirá o estudo da História da África e dos Africanos, a luta dos negros no Brasil, a cultura negra brasileira e o negro na formação da sociedade nacional, resgatando a contribuição do povo negro nas áreas social, econômica e política pertinentes à História do Brasil.

$\S 2^{\circ}$ Os conteúdos referentes à História e Cultura Afro-Brasileira serão ministrados no âmbito de todo o currículo escolar, em especial nas áreas de Educação Artística e de Literatura e História Brasileiras.

Art. 79-B. O calendário escolar incluirá o dia 20 de novembro como 'Dia Nacional da Consciência Negra'. ${ }^{1}$

Como é possível perceber através da leitura do texto da lei, não fica estabelecido quais conteúdos devem ser ensinados ou como devem ser ensinados, o que faculta diversas possibilidades de trabalho em sala de aula, evitando que o professor da educação básica fique com os conteúdos "engessados" no que tange a temática. Contudo, o que por um lado abre um leque para múltiplas possibilidades em sala de aula, por outro criou algumas dificuldades. $\mathrm{O}$ texto da lei não define os conteúdos a serem ministrados, fator que dificultou a presença das temáticas

\footnotetext{
${ }^{1}$ Lei no. 10.639 de 20 de janeiro de 2003. Disponível em: http://www.planalto.gov.br/ccivil 03/leis/2003/l10.639.htm . Consultado em 10/12/2014.
} 
africanas e afro-brasileiras em sala de aula, uma vez que a grande maioria dos professores não possuíam conhecimento e formação para aborda-las, ou muitas vezes negligenciavam a temática ${ }^{2}$.

Em 10 de março de 2008 foi publicada a lei 11.645, que acrescentava ao conteúdo da lei 10.639 a obrigatoriedade do ensino de história indígena em todas as séries da educação básica:

Lei no. 11.645 de 10 de março de 2008. Altera a Lei nำ 9.394, de 20 de dezembro de 1996, modificada pela Lei $\mathrm{n}^{\circ}$ 10.639, de 9 de janeiro de 2003, que estabelece as diretrizes e bases da educação nacional, para incluir no currículo oficial da rede de ensino a obrigatoriedade da temática "História e Cultura Afro-Brasileira e Indígena".

Art. $1^{\circ} \mathrm{O}$ art. 26-A da Lei $\mathrm{n}^{\circ}$ 9.394, de 20 de dezembro de 1996, passa a vigorar com a seguinte redação:

Art. 26-A. Nos estabelecimentos de ensino fundamental e de ensino médio, públicos e privados, torna-se obrigatório o estudo da história e cultura afro-brasileira e indígena.

$\S 1^{\circ}$ O conteúdo programático a que se refere este artigo incluirá diversos aspectos da história e da cultura que caracterizam a formação da população brasileira, a partir desses dois grupos étnicos, tais como o estudo da história da África e dos africanos, a luta dos negros e dos povos indígenas no Brasil, a cultura negra e indígena brasileira e o negro e o índio na formação da sociedade nacional, resgatando as suas contribuições nas áreas social, econômica e política, pertinentes à história do Brasil.

$\S 2^{\circ}$ Os conteúdos referentes à história e cultura afro-brasileira e dos povos indígenas brasileiros serão ministrados no âmbito de todo o currículo escolar, em especial nas áreas de educação artística e de literatura e história brasileiras. ${ }^{3}$

Tão importante quanto conhecer as leis que instituem a obrigatoriedade do ensino de história da África no Brasil é pensar porque elas foram criadas. Segundo o historiador Joseph KiZerbo, não é possível viver sem memória ou com a memória de outrem, ao menos que fosse feita uma escolha pela inconsciência e alienação, uma vez que ele considera a história como a memória dos povos. Ainda segundo o autor, "esse retorno a si mesmo pode, aliás, revestir-se do valor de uma catarse libertadora, como acontece com o processo de submersão em si próprio efetivado pela psicanálise, que, ao revelar as bases dos entraves de nossa personalidade, desata de uma só vez os complexos que atrelam nossa consciência às raízes profundas do subconsciente" ${ }^{4}$.

Assim, para que a história ensinada e aprendida na sala de aula permita ao aluno conhecer o passado para conseguir atuar sobre o presente e transformá-lo, é preciso que o conteúdo da disciplina diga respeito ao aluno, que ele consiga se sentir parte da narrativa histórica

\footnotetext{
${ }^{2}$ Essas dificuldades são abordadas por Anderson Ribeiro Oliva em: OLIVA, Anderson Ribeiro. "A História da África nos bancos escolares. Representações em impressões na literatura didática". Estudos Afro-Asiaticos. Rio de Janeiro, no. 25, no 3, 2003, pp. 421-461.

3 Lei 11.645 de 10 de março de 2008. Disponível em: http://www.planalto.gov.br/ccivil_03/_ato20072010/2008/lei/l11645.htm . Consultado em 10/12/2014.

${ }^{4} \mathrm{KI}-Z E R B O$, Joseph. "Introdução geral”. In: KI-ZERBO, Joseph (org.). História geral da África I - metodologia e préhistória da África. Brasília: UNESCO, 2010, pp. XXXI-LVII.
} 
apresentada, e não excluído, invisibilizado ou desfigurado por representação passiva e subjugadora.

Ciente disso, é preciso ter em mente que, de acordo com os dados coletados pela Pesquisa Nacional por Amostra de Domicílios (Pnad) promovida em 2014 pelo Instituto Brasileiro de Geografia e Estatística (IBGE), quase $54 \%$ da população brasileira se autodeclara "parda" ou "preta" ${ }^{5}$. Portanto, quando trazemos as histórias e as culturas dos africanos e dos afro-brasileiros para a sala de aula estamos tratando de um tema que metade da população reconhece estar ligado às suas origens, mas que, sobretudo, diz muito a respeito das origens e da nossa identidade enquanto nação.

Contudo, quando a lei 10.639/2003 foi promulgada, conhecimentos dos temas de história e cultura da África e dos afro-brasileiros eram ignorados por boa parte dos professores da educação básica, o que se constituía em um fator decisivo para que a temática fosse pouco abordada em sala de aula. Como exemplo, vale lembrar que em 2003, ano em que foi criada a lei 10.639, dos 211 cursos de graduação em história vigentes no país, apenas 62 deles, ou 29\%, ofereciam a disciplina de História da África aos graduandos ${ }^{6}$. Além do desconhecimento dos conteúdos, há ainda o desinteresse e o preconceito de docentes, que percebem as novas diretrizes "como imposição do Estado ou 'lei dos negros' ", como aponta Nilma Lino Gomes?.

\footnotetext{
${ }^{5} \mathrm{O}$ percentual de brasileiros que alega não ser branco cresce a cada ano, de acordo com os dados do Pnad 2014. Em $200451,2 \%$ dos entrevistados se definiram que sua "cor ou raça" é branca, 42,2\% disseram ser parda e 5,9\% consideravam ser preta, perfazendo um total de 48,1\% de pardos e pretos. Em 2007 foi a primeira vez que a população preta e parda superou a branca, desde que o critério de auto declaração foi instituído: neste ano $49,2 \%$ responderam que sua "cor ou raça" era "branca", 42,5\% "parda" e 7,5\% "preta", correspondendo a soma das suas últimas a $50 \%$. Desde então, tem sido crescente o percentual de indivíduos que se autodeclaram como "pretos" e "pardos". Em 2014, 45,5\% afirmaram que sua "cor ou raça" era "branca", 45\% "parda" e 8,6\% "preta", chegando a um total de $53,6 \%$ de pretos e pardos. Se essa tendência se mantiver, nos próximos anos a população branca deve ser superada pela parda. Essa mudança pode ser lida como fruto de um conjunto de ações afirmativas que tem buscado incentivar as diferenças étnico-raciais e lançando medidas de combate ao preconceito. Ainda que seja necessário expandir significativamente essas ações, o resultado delas já começa a ser notado na forma como a população se reconhece. IBGE. Pesquisa Nacional por Amostra de Domicílios - Síntese de Indicadores 2014. Disponível em: http://www.ibge.gov.br/home/presidencia/noticias/imprensa/ppts/00000024052411102015241013178959.pdf, consultado em 19/05/2016.

${ }^{6}$ Os dados acerca dos cursos de graduação em história se baseiam nos dados levantados pelo Instituto Nacional de Estudos e Pesquisas Educacionais (INEP) sobre o Exame Nacional de Cursos (ENC) realizado em 2003. Vide: OLIVA, Anderson Ribeiro. Lições sobre a África: diálogos entre as representações dos africanos no imaginário Ocidental e o ensino de história da África no Mundo Atlântico (1990-2005). Doutorado em História Social. Universidade de Brasília, Brasília, 2007, pp. 222.

${ }^{7}$ LINO GOMES, Nilma; EDNILSON DE JESUS, Rodrigo. As práticas pedagógicas de trabalho com relações étnico-raciais na escola na perspectiva de Lei 10.639/2003: desafios para a política educacional e indagações para a pesquisa. Educar em Revista, núm. 47, janeiro-março/2013, pp. 19-33, p. 31.
} 
Segundo a educadora, essas duas posturas por parte dos professores constituem as principais barreiras à implementação dos conteúdos nas escolas.

Passados mais de dez anos da criação da lei 10.639, o cenário começa a mudar. Diversas iniciativas ligadas à promoção do ensino de história e cultura africana e afro-brasileira têm auxiliado a fazer com os professores percebam a importância de se tratar da temática em sala de aula. Além disso, uma nova geração de professores recém-egressos do ensino superior, formados após a promulgação da lei 10.639, adentra as escolas com um olhar mais sensível para as temáticas ligadas à história da África. Some-se à isso iniciativas, ainda tímidas, nas esferas federal, estadual e municipal de ensino que tem levado editoras a incluírem capítulos dedicados à história da África em seus materiais didáticos, para não mencionar o crescente número de obras de literatura de autoria de escritores africanos e de livros das áreas de história e ciências sociais dedicados ao continente africano que vem sendo publicados no Brasil $^{8}$. Pode-se questionar o teor do conteúdo de história da África nos materiais didáticos, ou ainda as razões que fazem com que determinado autor africano seja selecionado para ser publicado no Brasil em detrimento de outros, contudo é inegável o aumento do número de publicações que abrangem temas de história da África no mercado editorial brasileiro 9 .

\section{A tipologia da consciência histórica em Jörn Rüsen}

O conceito de consciência história, tal como definido por Jörn Rüsen comporta maneiras de olhar e se relacionar com o passado orientada por valores morais, que trás um impacto direto para a situação presente e desenha um horizonte de expectativas para o futuro ${ }^{10}$. Por valores morais entende-se "geralmente princípios, guias de comportamento, ideias ou perspectivaschaves que sugerem o que deveria ser feito em uma situação determinada, em que existem várias

\footnotetext{
${ }^{8}$ A incipiência da questão, a crescente presença de obras dedicadas à história da África no mercado editorial bem como o aumento da existência de livros didáticos com parte de seu conteúdo dedicada à história da África, nos impede de trazer dados mais precisos acerca do tema pela carência de estudos dedicados à questão. Contudo, este aumento é facilmente perceptível se observada a data de publicação de obras acerca da temática.

${ }^{9}$ Sobre esse tema vide: OLIVA, Anderson Ribeiro. "A História da África nos bancos escolares. Representações em impressões na literatura didática". Estudos Afro-Asiaticos. Rio de Janeiro, no. 25, no 3, 2003, pp. 421-461.

10 KOSELLECK, Reinhart. Futuro Passado - contribuição à semântica dos tempos históricos. Rio de Janeiro: Contraponto, 2006.
} 
opções"11. Como afirma Rüsen, sem ter a dimensão do passado a compreensão do presente é prejudicada e a perspectiva do futura é uma cenário nebuloso: "A consciência histórica mistura "ser" e "dever" em uma narração significativa que refere acontecimentos passados com o objetivo de fazer inteligível o presente, e conferir uma perspectiva futura a essa atividade atual”12.

Assim, ainda segundo Rüsen, a consciência histórica adquire uma aplicação prática à vida cotidiana, na medida em que ela confere uma orientação temporal, ela atua como um guia intencional nas tomadas de decisões. Isabel Barca destaca que, por essa característica, a ideia de consciência histórica possibilita ao ser humano "uma visão de mundo muito maior à que esta confinado pela à sua própria experiência da vida quotidiana"(sic) ${ }^{13}$. Foi sobretudo por esta dimensão do conceito que o elegemos para análisar como os alunos se relacionam com as temáticas ligadas à história da África. Conforme já dito, o ensino de história da África foi estabelecido, entre outros aspectos, também por questões de ordem prática: buscar através dessa história, recuperar a memória e história da população afro-brasileira e do Brasil, como nação.

Estabelecendo diálogos com intelectuais que pensam a teoria do desenvolvimento da consciência moral, como Jean Piaget e Lawrence Kohlberg, Rüsen elabora uma tipologia para buscar compreender as etapas do desenvolvimento estrutural da consciência histórica. Os quatro tipo de consciência histórica são: tradicional; exemplar; crítico e genético.

O tipo tradicional se orienta pelas tradições e a consciência histórica opera para mantelas vivas. O passado se apresenta como algo fixo e imutável, sem distinções elaboradas entre uma época e outra. As tradições definem ainda a identidade histórica do indivíduo e sustentam modelos culturais predeterminados. Exemplo disso são os discursos comemorativos e monumentos públicos ${ }^{14}$.

O tipo exemplar por sua vez não se pauta pelas tradições, mas sim pelas regras. Aqui a história tem uma função didática de ensinar através dos exemplos do passado lições para serem aplicadas ao presente. Trata-se da concepção de historia magistra vitae, ou a "história mestra da

\footnotetext{
${ }^{11}$ RUSEN, Jörn. “O desenvolvimento da competência narrativa na aprendizagem histórica: uma hipótese ontogenética relativa à consciência moral”. In: SCHIMIDT, Maria Auxiliadora; BARCA, Isabel; MARTINS, Estevão de Rezende. Jörn Rüsen e o ensino de história. Curitiba, Editora UFPR, 2010, pp. 51-77, p. 55.

12 Idem, p. 57.

13 BARCA, Isabel. "Narrativas históricas de alunos em espaços lusófonos". In: BARCA, Isabel. Educação e consciência histórica na era da globalização. Braga: ClEd, Universidade do Minho, Associação de Professores de História, 2011, pp.7-27, p. 7.

${ }^{14}$ RUSEN, Jörn. “O desenvolvimento ..." Op. Cit., p. 63-64.
} 
vida", modelo reinante até aproximadamente a época moderna na historiografia tradicional, como ensina Reinhart Koselleck ${ }^{15}$. No tipo exemplar:

A tradição se move dentro de um marco de referência empírica bastante estreita, mas a memória histórica estruturada em termos de exemplos está aberta para processos em número infinito de acontecimentos passados, desde o momento em que estes não possuem relação com uma ideia abstrata de mudança temporal e de conduta humana, válido para todo tempo, ou ao menos cuja validade não esta limitada a um acontecimento específico. ${ }^{16}$

O tipo crítico recusa determinada construção do passado e busca criar uma outra versão dele. É o tipo que busca uma "contranarração" ${ }^{17}$, que desacredita determinada versão da história alegando ser falsa. Ele busca construir através da negativa ao recusar o papel de prisioneiro de estruturas determinantes ${ }^{18}$.

Por fim, o tipo genético aceita a história, mas identifica que a mudança e a plasticidade são o que lhe confere sentido. Esta é a sua principal característica. A história aqui não é tradição, modelo ou farsa, mas sim uma forma de compreender o mundo. Ele aceita a coexistência de diferentes pontos-de-vista porque compreende que esta pluralidade conforma um quadro de mudanças temporais.

Rüsen atenta que cada um dos tipo é precondição para o tipo seguinte, sendo observável uma maior complexidade, especificação e diferenciação conforme se passa de um tipo para outro. Apesar disso, o autor afirma os tipos normalmente aparecem em "mesclas complexas" e é necessário investigar com a devida atenção os resultados. Assim, os tipos tradicional e exemplar são encontrados com frequência, ao passo que os tipos crítico e genético são mais raros, isso porque a progressão dos tipos está ligada a complexificação do intelecto humano.

Nas escolas, a forma tradicional tem se mostrado como a mais facilmente aprendida, ao passo que a forma exemplar é a predominate nos currículos escolares. Já as formas críticas e genéticas são mais raras, já que requerem um grande esforço intelectual por parte do aluno e do professor ${ }^{19}$.

\footnotetext{
${ }^{15}$ Sobre esta temática ver: KOSELLECK, Reinhart. "História Magistra Viate - Sobre a dissolução do topos na história moderna em movimento". In: Futuro Passado...Op Cit., pp. 41-60.

${ }^{16}$ RUSEN, Jörn. “O desenvolvimento ...” Op. Cit p. 65.

${ }^{17}$ Termo empregado pelo autor. Cf.: Idem.

${ }^{18}$ Idem, p. 67.

${ }^{19}$ Ibidem, p. 74.
} 1, volume 1, Janeiro - Junho de 2016. 
Para Rüsen, a narrativa é o meio através do qual a consciência histórica é externalizada, seja ela um "relato descritivo-explicativo do passado, ou apenas narrativas abreviadas ("Portugal, um país de marinheiros", por exemplo), ou símbolos identitários (uma tradição peculiar)" 20 .

\section{A experiência do trabalho de campo e a elaboração do instrumento de pesquisa}

O trabalho de campo foi realizado em uma Escola Municipal de Ensino Fundamental (EMEF), localizada no centro expandido de São Paulo durante o mês de novembro de 2014. A escola contava com nove turmas de alunos do Ensino Fundamental, com uma média de vinte e cinco a trinta alunos por sala. Mesmo se tratando de uma escola da rede municipal de ensino, a escola padece de questões que são mais recorrentes na rede estadual, como a constante falta de professores. Além disso, boa parte dos alunos dos sétimo, oitavo e nono ano trabalhavam.

A escola foi selecionada para a realização do trabalho de campo porque possuía o perfil "médio" das escolas da rede municipal no que tange o ensino de história e cultura da África e dos afro-brasileiros: alguns professores desenvolviam algumas pequenas atividades ou dedicavam momentos das suas aulas para tratar do tema, mas essas iniciativas não se convertiam em projetos mais abrangentes, interdisciplinares e com um propósito pedagógico bem delimitado.

$\mathrm{Na}$ escola, os primeiros contatos foram realizados com a coordenadora pedagógica e com o professor de história substituto (a professora efetiva estava afastada há mais de quatro meses), ambos devidamente informados sobre a proposta de trabalho, qual fosse fazer uma reflexão sobre da percepção dos alunos acerca da história da África. O professor apresentou o material didático de história adotado pela escola, e como as temáticas africanas apareciam no material. Ele frisou que tinha uma preocupação em trabalhar temáticas ligadas à história e às culturas africanas em sala de aula, o que se confirmou com o desenrolar do trabalho de campo. Esse foi um dado definidor para a pesquisa: saber se os alunos tinham ou não contato com conteúdos relacionados à história da África.

A permanência na escola aconteceu na última quinzena de outubro e ao longo mês de novembro, escolhido por ser o mês da consciência negra no calendário da rede municipal,

\footnotetext{
${ }^{20}$ RUSEN, Jörn. Apud: BARCA, Isabel. "Narrativas históricas de alunos em espaços lusófonos”. In: BARCA, Isabel. Educação e consciência histórica na era da globalização. Braga: CIEd, Universidade do Minho, Associação de Professores de História, 2011, pp. 7-27.
} 1, volume 1, Janeiro - Junho de 2016. 
momento no qual há uma ênfase maior nas temáticas relacionadas a cultura e história africana e afro-brasileira, como foi possível constatar. Na ocasião a escola recebeu um grande lote de livros adequados às séries do ensino fundamental, que compreendiam desde contos de comunidades da África Ocidental, apresentados em uma bela edição com ilustrações, em um formato adequado para crianças das séries iniciais, até exemplares de títulos do escritor angolano José Luandino Vieira, pensados para serem trabalhados por alunos dos oitavo e nono anos. Os livros ficavam armazenados em uma pequena sala, cujo acesso só era possível de ser feito pela sala dos professores, logo, os alunos não tinham acesso nem conhecimento dos títulos ali presentes. Alguns professores fizeram uso das obras em suas aulas, como a professora de língua portuguesa, que ensinou a conjugação de verbos para alunos do 4ㅇ. ano a partir de um conto ashanti ${ }^{21}$. Entretanto, nos últimos dias do mês de novembro boa parte dos livros ainda estava envolta no plástico.

Para pensar a elaboração do instrumento de pesquisa, a estratégia inicial foi buscar conversar com os alunos para tentar fazer com que através de perguntas eles compartilhassem uma narrativa relativa à história da África. A primeira dificuldade foi conseguir conversar com os alunos: o intervalo durava apenas 10 minutos, e os alunos naturalmente e compreensivelmente preferiam interagir com os colegas e garantir a merenda. Os professores não se mostraram dispostos a liberar alguns alunos, mesmo que por alguns minutos durante suas aulas para que eu pudesse fazer tentar fazer as perguntas. A saída encontrada foi conversar com os alunos durante a educação física, por alguns minutos entrecortados de jogos.

Fazer perguntas que demandavam como resposta uma narrativa descritiva-explicativa acerca da história da África se mostrou algo mais complexo do que pode parecer à primeira vista: diferente de temas ligados à história do Brasil, da América e da Europa, que os alunos têm alguma noção desde cedo (descobrimento do Brasil e da América, independência do Brasil, Segunda Guerra Mundial, entre outros), em relação à história endógena da África, não havia um tema que fosse de conhecimento comum dos alunos principalmente porque se trata de um conteúdo relativamente novo no currículo escolar nacional e porque como a legislação não define como deve ser ministrado, os alunos que estudaram com professores diferentes em anos anteriores haviam aprendido conteúdos distintos acerca da história africana. Tentei reduzir a escala para os alunos de uma mesma série, mas nem assim foi possível reverter o quadro uma vez que alguns

\footnotetext{
${ }^{21}$ Os ashanti são uma comunidade étnica do interior de Gana, país situado África Ocidental.
} 1, volume 1, Janeiro - Junho de 2016. 
alunos haviam sido transferidos para a escola ao longo do ano letivo, mas principalmente porque os alunos haviam perdido muitas aulas de história em função do afastamento da professora, o que fez com que os conteúdos estivessem muito atrasados. Frente a essas questões, a ideia de criar um instrumento de pesquisa que implicasse em respostas que o aluno teria de desenvolver uma narrativa descritiva-explicativa pareceu arriscado e até certo ponto, algo que poderia criar disparidades a priori entre os alunos, o que comprometeria o resultado final.

Por essas razões foi elaborado um instrumento de pesquisa que analisasse narrativas abreviadas inteiramente criadas pelos alunos acerca da história da África. Ao invés de perguntar sobre um recorte específico, seria perguntado o que o aluno havia aprendido sobre a África e sua história. Essa escolha se deu porque nas conversas com os alunos, ao longo do processo de elaboração do instrumento de pesquisa, foram muito recorrentes falas como "antes de aprender sobre a África na aula, eu não sabia nada sobre lá, só que tinha tido a copa do mundo lá" (Pedro, 13 anos, 6‥ ano), ou ainda "antes eu achava que na África só tinha gente morrendo de fome e muita guerra, agora eu sei que lá tem cristãos e muçulmanos, brancos e negros" (Bruna, 14 anos, 70. ano $)^{22}$. Esse tipo de divisão entre o que os alunos sabiam antes das aulas de história da África, e os conhecimentos que adquiriram depois das aulas eram recorrentes nas conversas. Por isso, foi incorporada esta divisão ao instrumento de pesquisa como uma forma de tentar fazer com que os alunos realizassem narrativas abreviadas um pouco mais elaboradas. Foi também uma aposta no sentido de que essa divisão permitiria analisar com mais detalhes as formas de consciência histórica encontradas. Assim, a primeira parte do instrumento de pesquisa foi constituída por duas questões: 1) "Escreva no espaço abaixo o que você sabia no início do ano sobre a África e os africanos. Se você não havia aprendido nada sobre estes temas, escreva o que você pensava sobre eles."; 2) "Escreva no espaço abaixo o que você aprendeu ao longo deste ano sobre a África e os africanos $^{\prime 23}$. Foi ressaltado para os alunos que eles deveriam discorrer sobre os conhecimentos históricos que possuíam sobre o tema.

A segunda parte do instrumento de pesquisa é um exercício de associação de palavras, no qual os alunos deveriam circular palavras que associassem à África e aos africanos. Ao todo eram trinta e duas palavras dispostas em quatro colunas com oito palavras ${ }^{24}$ em cada uma e o aluno

\footnotetext{
${ }^{22}$ Fonte: anotações pessoais das conversas tidas com os alunos no caderno de campo.

${ }^{23}$ Grifos reproduzidos tal como no instrumento de pesquisa.

24 As palavras eram: Coluna 1) "comércio"; "conhecimento"; "cristãos"; "primitivo"; "artes"; "celular"; "história"; "quilombo"; Coluna 2) "música"; “cultura"; "agricultura"; "guerras"; "muçulmanos"; "escravidão"; "Brasil”; "animais";
} 
poderia assinalar quantas palavras quisesse, tal como indicava o comando da seção: "3) Circule quais palavras você associa à África e aos africanos" ${ }^{25}$. O intuito era conseguir aprofundar um pouco mais as narrativas abreviadas, já que alguns alunos davam respostas muito curtas, buscando mapear com um pouco mais de precisão as percepções. Esta segunda parte foi pensada, portanto, para ser um complemento à primeira, para auxiliar a compreender melhor as relações estabelecidas pelos alunos em relação ao tema.

A fim de não direcionar os resultados e também fazer com que o aluno refletisse antes de assinalar, foram listadas palavras que dialogavam com uma referencial positivo acerca do continente (como "cultura", "artes", "música" e "conhecimento"), quanto palavras que invocavam referências negativas (por exemplo "guerra", "fome" e "racismo"). Também foram colocadas palavras que permitiam pensar se as percepções históricas e culturais são realizadas sobretudo a partir de elementos da cultura afro-brasileira ou não (como "capoeira" e "quilombo") e em que medida referências africanas fazem parte ou não parte do repertório histórico e cultural dos alunos (a partir do uso das palavras "pirâmides" e "Tombuctu" ${ }^{26}$ ). Além disso, haviam também palavras que traziam noções de diversidade ("cristãos" e "muçulmanos"), termos que correspondiam a conteúdos acerca do continente que haviam sido trabalhadas em sala de aula como os conhecimentos de técnicas de manuseio do ferro, cobre e ouro pelas sociedades africanas ("ferro e ouro") e vocábulos que seriam provavelmente só seriam assinalados por alunos que possuíssem uma percepção que não estivesse presa aos estereótipos relacionados ao continente (como "celular"). Os instrumentos de pesquisa, tal como indica Rüsen, também traziam campos para a identificação da série e idade dos alunos ${ }^{27}$.

Ao longo do trabalho de campo, um dos professores de geografia da escola estava ministrando aulas sobre geografia física e humana da África para uma de suas turmas e fez um permitiu que suas aulas fossem acompanhadas para os fins do estudo. Debates sobre a África e os africanos acerca de questões de história do tempo presente, como o apartheid e a conjuntura conhecida como "primavera árabe", estavam sempre presentes nas aulas. Após apresentar as diretrizes do estudo em curso ao professor, ficou combinado que o instrumento de pesquisa seria

Coluna 3) "escolas"; “aldeia”; "Tombuctu”; "pirâmides"; "doenças"; "natureza”; “escrita”; "resistência”; Coluna 4) "racismo"; "ferro e ouro"; "desenvolvimento; "tecidos"; "capoeira"; "fome"; "Egito"; "computador".

25 Idem.

${ }^{26} \mathrm{O}$ vocábulo foi elencado porquê, de acordo com o professor de história, a cidade de Tombuctu havia sido abordada quando os alunos estudaram história medieval.

${ }^{27}$ RUSEN, Jörn. “O desenvolvimento ...”.Op. Cit, p. 76-77. 
aplicado aos alunos ao final de uma aula. A possibilidade de poder aplica-lo a toda a sala e posteriormente poder examinar as diferenças e aproximações na forma como alunos de uma mesma turma refletiram acerca das questões propostas, revelou-se um ponto importante, uma vez que revela como uma turma que foi exposta aos mesmos conteúdos os apreende e imprime sentido a eles de formas muito distintas.

\section{Análise das narrativas abreviadas}

Conforme ressalta Rüsen, a análise das narrativas para tentar perceber o tipo de consciência histórica é um processo complexo e muitas vezes intrincado, que não se pauta pela abrangência do conhecimento do indivíduo sobre o tema, mas sim a forma como ele encara o assunto, como ele se porta e exterioriza sua visão sobre o mesmo.

Foram analisadas as respostas de 24 estudantes do 8 . ano, com idade entre doze e dezessete anos, sendo a média de idade 13 anos. Pelos limites deste estudo não seria possível transcrever as vinte e quatro respostas, então foi feita a opção por selecionar algumas que mais emblemáticas e analisa-las com mais vagar. Durante a aplicação do instrumento de pesquisa, foi notado que mesmo se tratando de alunos do $8^{\circ}$. ano, alguns estudantes tinham um certo grau de dificuldade de escrever com agilidade, tanto porque suas habilidades motoras eram tanto mais lentas do que se pode esperar de um aluno dessa série, quanto porque esboçavam dificuldades para criar um texto escrito como resposta.

Pela análise do conjunto das respostas, foi possível perceber a grande maioria dos alunos possuí uma consciência histórica de tipo tradicional. Em todas as respostas, os alunos afirmam que aprenderam novos conteúdos sobre a África e chegam a citar entre seus novos conhecimentos exemplos históricos, como o apartheid e a diáspora africana para a América (referenciada pelos alunos como "escravidão). Contudo, como já colocado, essa característica por si só não é um indicativo de uma mudança na consciência histórica, como veremos na análise de três respostas a seguir.

Conforme já exposto, o tipo tradicional se guia pelas tradições, e enxerga o passado tradicional como algo fixo e estático. Ao analisar as resposta fornecidas pela aluna Sabrina, 12 anos, essas características se fazem presentes: 
1) Escreva no espaço abaixo o que você sabia no início do ano sobre a África e os africanos. Se você não havia aprendido nada sobre estes temas, escreva o que você pensava sobre eles.

"Eu não sabia nada".

2) Escreva no espaço abaixo o que você aprendeu ao longo deste ano sobre a África e os africanos.

"Eu aprendi, que mesmo os africanos sofrendo o que eles sofrem, com doenças, fome, escravidão, racismo, miséria, guerras, etc. poderião ter uma vida melhor, diguina mas eles não podem por causa da escravidão etc... poderião ter ajuda os africanos, mas não tem condições da África ter escolas, alimentação, hospitais" $(\mathrm{sic})^{28}$

Alguns elementos presentes nesta narrativa abreviada corroboram para caracterizar a consciência histórica da aluna como uma consciência do tipo tradicional: a escravidão é assinalada como um marco que explica, na visão da aluna, porque no presente há na África "doenças, fome, escravidão, racismo, miséria, guerras". Pela resposta da aluna, a escravidão também pode ser entendida como a explicação para que no tempo presente a África não tenha "escolas, alimentação, hospitais". Dito de outra forma, o raciocínio na aluna percebe que como ocorreu a "escravidão" no passado, o presente e o futuro estão também amarrados indissociavelmente desta condição, o que impede que na África tenha "escolas, alimentação, hospitais", condições básicas para que ocorra o uma melhoria das condições de vida e que também não se fizeram presentes ou foram extremanente deficitárias (no caso nos referimos à alimentação) no período da escravidão.

Entre as palavras assinaladas pela aluna na segunda parte, destacam-se os termos "miséria", "guerras", "escravidão", "doenças", "racismo" e "fome" como termos que podem ser associados às características de valoração negativa atribuídas pela aluna como uma herança da escravidão no presente. A aluna também assinalou termos como "escola", "aldeia" e "desenvolvimento", que podem ser relacionados à parte final da sua resposta. Por fim, uma associação entre os termos "capoeira" e "escravidão", ambos circulados pela aluna, conduzem a um entendimento que a escravidão que ela faz eferência se trata da escravização dos africanos para servirem de mão-de-obra no Brasil, e provavelmente não da escravização interna na África ou na América. Partindo desta hispótese, vale notar que a explicação fornecida pela aluna se sustenta em uma situação histórica ocorrida no Brasil e na África, mas associada por ela ao Brasil, para explicar a visão que ela tem sobre o continente africano no presente.

\footnotetext{
${ }^{28}$ Todas os instrumentos de pesquisa com as respostas dos alunos encontram-se nos anexos.
} 1, volume 1, Janeiro - Junho de 2016. 
O tipo subsequente ao tradicional é o tipo exemplar. Esse tipo se pauta pelas regras, e não pelas tradições, e está baseado na noção de historia magistra vitae ("história mestra da vida"), segundo a qual os exemplos históricos servem de auxiliam a tomar decisões e agir no presente. Podemos perceber esse tipo de relação com o passado na resposta do aluno Juan, de 13 anos. Juan afirma:

1) Escreva no espaço abaixo o que você sabia no início do ano sobre a África e os africanos. Se você não havia aprendido nada sobre estes temas, escreva o que você pensava sobre eles.

"No início eu achava que a África era só pessoas e etnias negras e que eles viviam de uma qualidade de vida boa e que era pobreza e só tinha pessoas doentes."(sic) 2) Escreva no espaço abaixo o que você aprendeu ao longo deste ano sobre a África e os africanos.

“Eu aprendi que a África não é só negros, também brancos em minoria, tem países ricos e pobres (a maioria pobre). E o racismo era muito grande lá e que tem lugares (muitos) com vida ruim e pobre. E também que não devemos julgar a pessoa pela raça ou cor e sim pela característica dela." (sic)

A segunda resposta é particularmente reveladora. Na primeira frase o aluno afirma que aprendeu que na África vivem "negros" e "brancos", o que para ele é um dado histórico novo. Essa informação se articula com o início da segunda frase ("E o racismo era muito grande lá") que remete a uma situação conflituosa derivada do elemento fornecido na primeira frase. Na terceira e última frase, concluindo seu raciocínio, o aluno acrescenta "E também que não devemos julgar a pessoa pela raça ou cor e sim pela característica dela", que corresponde ao aprendizado que ele extraiu dessa situação histórica. Observemos como o aluno indica relação entre as três sentenças a partir do uso da conjunção "e" no início de cada frase, ("Eu aprendi que a África não é só negros (...)E o racismo era muito grande lá (...)E também que não devemos julgar a pessoa pela raça ou cor"), o que imprimi a sensação do desenrolar de uma mesma história que se encerra, assim como nas Fábulas de Esopo, com um ensinamento: "devemos julgar a pessoa pela raça ou cor e sim pela característica dela".

O terceiro tipo definido por Rüsen é o crítico. Este tipo constrói a partir da negação de determinada narrativa, uma "contranarração" histórica. Conforme já mencionamos, o autor afirma que sua tipologia corresponde a definição de modelos, contudo ao analisar uma narrativa é comum que eles não se apresentem em sua forma completa, que ou mesmo coexista mais de um modelo em uma mesma narrativa. As respostas fornecidas pela aluna Vitoria, 14 anos, apresentam essas "mesclas complexas", como caracteriza Rüsen: 
1) Escreva no espaço abaixo o que você sabia no início do ano sobre a África e os africanos. Se você não havia aprendido nada sobre estes temas, escreva o que você pensava sobre eles.

"Bom antes eu pensava que a África era simplismente pessoas negras que não tinham condições para comer ou para qualquer outra coisa. Pensava também que viviam na seca sem ter o que comer morar ou vestir. E que era um continente 'excluído'."(sic)

2) Escreva no espaço abaixo o que você aprendeu ao longo deste ano sobre a África e os africanos.

“Aprendi que a África não é só não é só miséria, que não é só pessoas negras, que não é só deserto e que muitos africanos e que muitos africanos são ricos e que ela também é dividida em 2 partes branca norte negros sul" (sic)

A resposta à primeira pergunta mostra uma forma de consciência histórica mais próxima da tradicional, forjada por estereotipos e preconceitos em relação à África e aos africanos. Uma possível aposta para esta análise é pensar que a aluna imaginava o continente africano como "exclúído" em função das situações de privação que ela expõe, mas também porque ainda hoje se aprende muito menos sobre história da África do que sobre a história européia nas escolas, criando para o aluno uma sensação de "vazio histórico". Na segunda pergunta a aluna se mostra crítica ao tipo de visão que ela possuía: a forma de externalizar a sua discordância é através da negação da percepção anterior, como se nota pela frase "Aprendi que a África não é só não é só miséria, que não é só pessoas negras, que não é só deserto (...)". O uso e repetição do termo "só" indica que a aluna percebe que a visão que ela possuía sobre a África era restrita. Contudo, seria um excesso afirmar que a narrativa da aluna na segunda questão se enquadra plenamente na forma crítica, uma vez que a aluna não chegou a apresentar uma "contranarração" dos postulados que ela mesma negou. Dito de outra forma, ela negou a visão que considerava estreita, mas não chegou propor um novo olhar àquilo que considera passível de críticas. Trata-se de uma consciência histórica em formação, já que como assegura Rüsen, ela pode sofrer mudanças conforme a escolaridade do aluno e seu desenvolvimento intelectual.

Por se tratarem de alunos jovens e em processo de aprendizagem não foi identificada nenhuma resposta que pudesse ser identificada com o tipo genético.

\section{Considerações finais: uma visão de conjunto}


A partir das respostas fornecidas pelos alunos do 8‥ ano apontam questões importantes para se pensar o ensino de história da África no Brasil. A primeira delas, e talvez seja esse o dado mais revelador, é a importância dos aprendizados na sala de aula para os conhecimentos dos alunos acerca do continente e sua história. Acostumados à imagens que representam a África como um espaço castigado pela "miséria", "fome", "doenças", "escravidão" e "guerras"29, o conhecimento obtido em sala de aula somou novas informações, possibilitou os alunos a conhecerem um pouco sobre a história do continente e em alguns casos fez com que os alunos reavaliassem os suas percepções anteriores acerca do continente e seus habitantes. Todos os alunos foram unanimes ao afirmar que obtiveram novos conhecimentos sobre a história da África ao longo do ano. As descobertas mais citadas foram que "a África não é um país"; que no continente também vivem "brancos" e "negros"; que na África vivem "muçulmanos" e que lá há "várias religiões"; que existem várias "culturas" e várias "etnias". Os alunos também aprenderam que o "que o Egito fica na África" e um aluno mencionou "a luta contra o apartheid". Contudo, no exercício de associação presente na segunda parte do instrumento de pesquisa, entre as palavras mais associadas à África, de um total de 24 alunos todos assinalaram a palavra "escravidão", 23 assinalaram as palavras "doenças" e "racismo" e 22 assinalaram a palavra "fome". Na contramão desta visão, 22 alunos assinalaram "cultura". Entre os termos menos assinalados estão "celular" e "computador", que não foram assinalados por nenhum dos alunos; "artes" e "tecidos" que foram assinalados quatro vezes; seguidos de "escolas", assinalado 5 vezes. Curiosamente, o professor havia exibido para os alunos na mesma aula imagens das ruas de Nairóbi, no Quênia, com diversas pessoas falando ao celular.

Articulando os resultados das duas partes do instrumento de pesquisa, é possível afirmar que ao passo que nas respostas dissertativas os resultados apontam uma visão que começa a se expandir e pensar um pouco além das formas tradicionais da consciência histórica, na segunda parte, os termos que correspondiam à visão que os alunos tinham acerca da África antes dos conhecimentos aprendidos em sala de aula foram as mais assinaladas. Essa divergência pode ser lida como expressão de um processo no qual o conhecimento sobre o tema está em construção, logo quando submetido a um exame que depende mais da subjetividade, como é o caso da segunda parte do instrumento de pesquisa, os alunos tenderam a dar respostas mais próximas daquilo que eles haviam visto anteriormente sobre a África, provavelmente porque é o que está

\footnotetext{
${ }^{29}$ Termos utilizados pelos alunos para descrever o que sabiam sobre a África no início do ano.
} 1, volume 1, Janeiro - Junho de 2016. 
mais consolidado entre os seus conhecimentos ${ }^{30}$. Assim, as respostas por vezes combinam representações preconceituosas e racistas com elementos que as questionam.

Em síntese, utilizando a tipologia da consciência histórica de Rusen como base, foi possível notar que o ensino de história da África tem avançado aos poucos nas escolas. Apesar da maior parte da respostas ir na direção de uma consciência histórica tradicional, o que não seria incomum entre alunos desta faixa etária, já que o autor aponta que os tipos tradicional e exemplar são os mais encontrados no ambiente escolar, também foi verificada uma percepção mais refinada por parte dos alunos, ao atribuirem sentido para os conhecimentos históricos aprendidos para analisar o presente (o caso do aluno Juan, identificado como tipo exemplar), e ao negar uma visão predeterminada da África (como no caso da aluna Vitória). Aos poucos os contornos começam a mudar, e a história da África começa a ser objeto de questionamento e aprendizado para os alunos. Contudo, como demonstram as respostas, ainda é preciso muito trabalho nesse sentido.

\section{Referências Bibliográficas}

\section{Fontes:}

IBGE. Pesquisa Nacional por Amostra de Domicílios - Síntese de Indicadores 2014. Disponível em: http://www.ibge.gov.br/home/presidencia/noticias/imprensa/ppts/000000240524111020152410 13178959.pdf, consultado em 19/05/2016.

Lei no. 10.639 de 20 de janeiro de 2003. Disponível em: http://www.planalto.gov.br/ccivil 03/leis/2003/l10.639.htm. Consultado em 10/12/2014.

Lei 11.645 de 10 de março de 2008. Disponível em: http://www.planalto.gov.br/ccivil_03/_ato2007-2010/2008/lei/l11645.htm . Consultado em 10/12/2014.

\section{Bibliografia secundária:}

\footnotetext{
${ }^{30}$ Rüsen prevê que os alunos possam apresentar elementos de diferentes tipos da consciência histórica conforme o fator que é ativado da consciência histórica (formas experiência do tempo, significação histórica, orientação da vida exterior, orientação da vida interior, relação com os valores morais, relação com o raciocínio moral). Vide: RUSEN, Jörn. "O desenvolvimento ..." Op. Cit., pp. 62-77.
} 1, volume 1, Janeiro - Junho de 2016. 
BARCA, Isabel. "Narrativas históricas de alunos em espaços lusófonos". In: BARCA, Isabel. Educação e consciência histórica na era da globalização. Braga: CIEd, Universidade do Minho, Associação de Professores de História, 2011, pp.7-27.

KI-ZERBO, Joseph. "Introdução geral". In: KI-ZERBO, Joseph (org.). História geral da África I metodologia e pré-história da África. Brasília: UNESCO, 2010, pp. XXXI-LVII.

KOSELLECK, Reinhart. Futuro Passado - contribuição à semântica dos tempos históricos. Rio de Janeiro: Contraponto, 2006.

LINO GOMES, Nilma; EDNILSON DE JESUS, Rodrigo. As práticas pedagógicas de trabalho com relações étnico-raciais na escola na perspectiva de Lei 10.639/2003: desafios para a política educacional e indagações para a pesquisa. Educar em Revista, núm. 47, janeiro-março/2013, pp. 19-33.

OLIVA, Anderson Ribeiro. "A História da África nos bancos escolares. Representações em impressões na literatura didática". Estudos Afro-Asiaticos. Rio de Janeiro, no. 25, no 3, 2003, pp. 421-461.

. Lições sobre a África: diálogos entre as representações dos africanos no imaginário Ocidental e o ensino de história da África no Mundo Atlântico (1990-2005). Doutorado em História Social. Universidade de Brasília, Brasília, 2007.

RUSEN, Jörn. "O desenvolvimento da competência narrativa na aprendizagem histórica: uma hipótese ontogenética relativa à consciência moral". In: SCHIMIDT, Maria Auxiliadora; BARCA, Isabel; MARTINS, Estevão de Rezende. Jörn Rüsen e o ensino de história. Curitiba, Editora UFPR, 2010, pp. 51-77.

SCHIMIDT, Maria Auxiliadora; GARCIA, Tania Maria. "A formação da consciência histórica de alunos e professores e o cotidiano em aulas de história. In: Cad. Cedes, Campinas, vol. 25, n. 67, p. 297-308, set./dez. 2005.

Helena Wakim Moreno: Possui graduação em História pela Universidade de São Paulo (2010) e mestrado em História Econômica pela Universidade de São Paulo (2014), com período sanduíche na Universidade de Lisboa (2013). Atualmente realiza sua pesquisa de doutoramento em História Social (2015). Foi professora do curso de Licenciatura em História da Faculdade Sumaré, atuando como professora de História da África, orientadora de Trabalhos de Conclusão de Curso (TCC) e membro do Núcleo Docente estruturante do curso. Tem experiência na área de História, com ênfase em História Moderna e Contemporânea, atuando principalmente nos seguintes temas: Colonialismo, História da África, História de Angola, Luanda, Escrita e Resistência, Imprensa, Relatos de Viagens.

Artigo recebido para publicação em: Maio de 2016.

Artigo aprovado para publicação em: Junho de 2016. 